\title{
Wound Healing Modulation in Glaucoma Filtration Surgery-Conventional Practices and New Perspectives: The Role of Antifibrotic Agents (Part I)
}

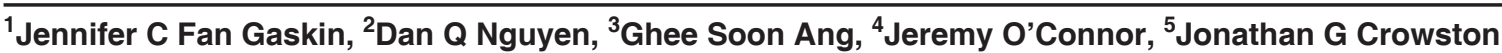

\begin{abstract}
Glaucoma filtration surgery is regularly performed for the treatment of glaucoma and trabeculectomy is often regarded as the 'gold standard' glaucoma operation. The biggest risk of failure of the operation is bleb scarring. The advent of anti-fibrotic agents, such as mitomycin C (MMC) and 5-fluorouracil (5FU) has vastly prolonged the longevity of the bleb, but concerns remain regarding the potential increase in postoperative complications. More selective therapeutic targets have therefore been explored. One of these is vascular endothelial growth factor (VEGF) inhibition. Vascular endothelial growth factor inhibition has a role not only in subconjunctival angiogenesis inhibition but also it has direct anti-fibrotic properties. Newer pharmacological compounds and materials have also been developed in recent years in attempt to modulate the wound healing in different ways after glaucoma surgery. These include physical barriers to scarring and vehicles for sustained release of pharmacological agents, and early promising results have been demonstrated. This two-part review will provide a discussion of the application of anti-fibrotic agents in glaucoma filtration surgery and evaluate the newer agents that have been developed.
\end{abstract}

Keywords: Glaucoma, Trabeculectomy, Filtration surgery, Antimetabolites, Wound healing modulation, Scarring.

How to cite this article: Fan Gaskin JC, Nguyen DQ, Ang GS, O'Connor J, Crowston JG. Wound Healing Modulation in Glaucoma Filtration Surgery-Conventional Practices and New Perspectives: The Role of Antifibrotic Agents (Part I). J Curr Glaucoma Pract 2014;8(2):37-45.

Source of support: Nil

Conflict of interest: None declared

\section{INTRODUCTION}

It has long been recognised that fibrosis of the filtration site is one of the main reasons for primary failure of glaucoma filtering surgery. Since the initial description of the use of

\footnotetext{
${ }^{1}$ Glaucoma Fellow, ${ }^{2-4}$ Consultant, ${ }^{5}$ Professor

$1,3,5$ Glaucoma Investigation and Research Unit, Centre for Eye Research, University of Melbourne, Melbourne, Australia

${ }^{2}$ Department of Ophthalmology, Mid Cheshire Hospitals, NHS Foundation Trust, Cheshire; Institute for Science and Technology in Medicine, Keele University, Keele, Staffordshire, UK

${ }^{4}$ Glaucoma Investigation and Research Unit, University Hospital Limerick, Ireland

Corresponding Author: Jennifer C Fan Gaskin, Glaucoma Fellow, Glaucoma Investigation and Research Unit, Centre for Eye Research, University of Melbourne, Melbourne, Victoria, Australia Phone: 0061406494994, e-mail: drjfan@gmail.com
}

mitomycin C (MMC) as an adjunct to trabeculectomy in 1983 by Chen, ${ }^{1}$ and echoed a year later by Gressel with 5 -fluorouracil $(5 \mathrm{FU}),{ }^{2}$ the filtering bleb has seen greater success both in its efficacy and longevity. These two agents have been widely adopted in an off-label capacity to combat tissue fibrosis following surgery. However, the use of anti-fibrotic agents is not without its risks and limitations. Other more alternative approaches to wound modulation in glaucoma surgery have therefore been explored in recent years, including anti-vascular endothelial growth factor (anti-VEGF). This two-part series will review the current practice in wound healing modulation in glaucoma surgery and explore the newer options on the horizon. Part one will provide an overview of the current use of MMC and 5FU as anti-fibrotic agents in glaucoma filtration surgery, and part two will discuss the use of anti-VEGF as well as other more novel agents/materials being developed.

\section{REVIEW}

\section{Rationale for Wound Healing Modulation}

A trabeculectomy bleb, like any other tissue, undergoes different phases of postoperative wound healing. ${ }^{3}$ The first phase is an immediate inflammatory response that occurs in the initial postoperative days. This phase is characterized by recruitment of inflammatory cells, cytokines and growth factors, triggering the onset of the second phase, proliferation and tissue reparation, which commences in the early postoperative days and can continue into the second or third postoperative months. The second phase comprises activation, migration and proliferation of episcleral fibroblasts, angiogenesis and the formation of collagen bundles. The third and final phase involves remodelling and final healing of the wound, when contraction of the collagen fibers and formation of scar tissue occurs, ultimately resulting in reduction of aqueous drainage and subconjunctival absorption. While healing under the scleral flap may play a role in some cases, it is the fibroblasts in Tenon's capsule that are the main effector cells in the initiation and mediation of trabeculectomy wound healing and fibrotic scar formation. ${ }^{4}$

The purpose of wound healing modulation is to moderate the healing process through pharmacological intervention. It involves the delicate balance of optimal conjunctival healing 
with the suppression of scar formation in the filtering bleb. In the most rudimentary form, it comprises the application of topical corticosteroid eye drops in the postoperative period. A more potent form of wound healing modulation requires the subtenons and/or sub-scleral flap application of an antimetabolite, such as MMC or 5FU intraoperatively; 5FU can also be applied as repeated subconjunctival injections postoperatively.

\section{Mechanism of Action and Administration of Mitomycin C}

Mitomycin C is an alkaloid produced by the bacterium Streptomyces caespitosus. The direct cytotoxic effect of MMC occurs through inhibition of DNA-dependent RNAsynthesis. ${ }^{5}$ Induction of apoptosis has been demonstrated in cultured human Tenon's fibroblasts following application of MMC (concentration range: $0.1-1.0 \mathrm{mg} / \mathrm{ml}$ ) for 5 minutes. ${ }^{6}$ The apoptotic process begins 48 hours after administration of MMC in vitro and the amount of apoptosis induced is dose-dependent. ${ }^{6}$ Mitomycin $\mathrm{C}$ has also been observed to increase the expression of apoptosis genes in human Tenon's fibroblasts. ${ }^{7}$ Mitomycin $\mathrm{C}$ contains quinine, urethane and aziridine, all of which have anti-tumor properties. It also has potent anti-angiogenic properties. ${ }^{8}$ The effect of intraoperative application of MMC has been demonstrated to be localized to the area it is exposed to. ${ }^{8}$ Furthermore, the intracellular activation of MMC to the active reduced form may occur more efficiently in ocular fibroblasts than in fibroblasts from other parts of the body. ${ }^{9}$ Therefore, the many properties of MMC are utilized during trabeculectomy to modulate wound healing in the subconjunctival space as well as Tenon's capsule. ${ }^{10}$

Mitomycin $\mathrm{C}$ is usually soaked into cellulose sponges and applied between the conjunctiva-Tenon's capsule and the sclera before scleral flap dissection; ${ }^{11,12}$ following scleral flap dissection with application under the scleral flap; ${ }^{4,13}$ or both. It has also been reported to be injected subconjunctivally rather than applied with cellulose sponges. ${ }^{14}$ El Sayyad et al demonstrated significantly lower IOP control in eyes treated with MMC application both under the scleral flap and the conjunctiva during trabeculectomy compared to under the scleral flap or conjunctival flap alone at 12 months followup. ${ }^{15}$ Similarly, Prata et al also found greater likelihood of achieving IOP $\leq 21 \mathrm{~mm} \mathrm{Hg}$ in eyes treated with MMC under the dissected scleral flap and conjunctiva compared to on the episclera alone, without any significant difference in rates of complication. ${ }^{16}$ However, in a fascinating study, Gandolfi et al demonstrated that IOP could be reduced merely by injecting MMC subconjunctivally without an accompanying trabeculectomy in eyes already blinded by glaucoma. This IOP-lowering effect was detectable even after 60 days of follow-up. ${ }^{17}$ As no alteration was made to the ocular outflow system during this study, the authors postulated that the reduction in IOP in fact resulted from the toxic effects of MMC diffusing into the ciliary body. This idea has been supported by earlier animal models. ${ }^{18,19}$ Increasing concentrations of MMC in the deeper scleral layers with increasing $\mathrm{MMC}$ diffusion time has also been demonstrated by Georgopoulos et al, ${ }^{20}$ who observed that after 1 minute application of $0.2 \mathrm{mg} / \mathrm{ml}$ of MMC to donor human sclera, there was no difference in MMC concentration across the sclera after 30 minute diffusion time. Since MMC continues to diffuse into the sclera following its application in human trabeculectomy, it is conceivable that MMC may damage the ciliary body and therefore result in a hypotonic effect.

The concentration of MMC used in glaucoma filtration surgery from 0.1 to $0.5 \mathrm{mg} / \mathrm{ml}$ in a dilution with balanced salt solution. The concentration and duration of application are determined arbitrarily by the surgeon, depending on their assessment of the patient and the risk of surgical failure. Vass et al. ${ }^{21}$ assessed the intrascleral concentration of MMC in different layers following episcleral application of varying concentrations of MMC $(0.01 \mathrm{mg} / \mathrm{ml}, 0.1 \mathrm{mg} / \mathrm{ml}$, $0.2 \mathrm{mg} / \mathrm{ml}$ ) in human donor sclera for 1 minute and identified statistically significant differences in the intrascleral concentrations of MMC with varying concentrations of applied MMC. There was a log-linear decrease in MMC concentration with increasing depth of sclera, and this was observed with all three MMC concentrations. However, thus far, the majority of clinical studies have failed to demonstrate a significant difference in final IOP based on variations in MMC concentration or exposure time. ${ }^{22-27}$ Only one study of 300 eyes has identified a possible dose-response relationship between the concentration and duration of exposure to MMC although the differences were not statistically significant. $^{28}$

Immediately following the application of MMC, the treated area and especially the surrounding conjunctiva is typically rinsed with 20 to $50 \mathrm{ml}$ of normal saline to prevent toxicity to the surrounding tissues. Vass et al. ${ }^{29}$ assessed the effect of saline irrigation on MMC treated human donor sclera and found decreased MMC concentration in the superficial layers of the sclera after irrigation compared to no irrigation. The concentration of MMC decreased in these layers with increasing volume of irrigating saline (40-200 ml). However, in the deeper scleral layers, irrigation made no difference to MMC concentration. It is worth noting that this study was conducted on scleral quadrants mounted on watertight shields that may have influenced the effect of irrigation on the deeper layers. It is possible that in vivo, irrigation does actually make a difference to the MMC concentration in the deep scleral layers. 


\section{Clinical Indications for}

\section{MMC-augmented Trabeculectomy}

Mitomycin C is inexpensive and simple to use as a one-off intraoperative application. The main reason that MMC has been so readily adopted by ophthalmologists is its efficacy in modulating post-trabeculectomy conjunctival scarring. A recent survey of United Kingdom (UK) glaucoma units revealed anti fibrotic use in $93 \%$ of its primary trabeculectomies with $63 \%$ being MMC. ${ }^{30}$ In contrast, in the 1995 UK National Survey of Trabeculectomy, only 6.4\% of trabeculectomies were performed with an adjunctive anti-fibrotic. ${ }^{31}$ A similar survey of the American Glaucoma Society found that MMC use in primary trabeculectomies increased from $45 \%$ in 1996 to $68 \%$ in $2002 .{ }^{32}$

Its efficacy is best illustrated by its use in trabeculectomy for primary open-angle glaucoma (POAG). Reibaldi et $\mathrm{al}^{33}$ conducted a randomized clinical trial comparing $0.2 \mathrm{mg} / \mathrm{ml} \mathrm{MMC}$ with balanced salt solution (BSS) applied intraoperatively on the episclera during trabeculectomy in 114 eyes of 114 patients. A significantly higher proportion of patients achieved IOP $\leq 18 \mathrm{~mm} \mathrm{Hg}$ without medication (71\% vs 51\%, $\mathrm{p}=0.027)$ and with $\mathrm{IOP} \leq 14 \mathrm{~mm} \mathrm{Hg}(57 \%$ vs $32 \%, \mathrm{p}=0.015)$ in the MMC-treated group compared to the BSS-treated group over a 9-year follow-up period. Correspondingly, a lower proportion in the MMC group developed visual field progression $(22 \% v s 47 \%, p=0.009)$ or required further glaucoma surgery $(9 \%$ vs $26 \%, \mathrm{p}=0.040)$ compared to the BSS group. Similar results have been demonstrated in other studies. ${ }^{34-36}$ In young adults ( $<40$ years), unaugmented trabeculectomy is less likely to be successful due to a more vigorous wound healing response and potential for scarring, ${ }^{37,38}$ but survival of the operation and postoperative IOP control can be improved with adjunctive MMC during surgery. ${ }^{39}$

In normal tension glaucoma (NTG), although filtering surgery may achieve a higher percentage of IOP reduction compared to topical medication, there is an increased rate of sight-threatening complications, such as late bleb leak and late hypotony when adjunctive MMC is administered. ${ }^{40}$ Although the authors have demonstrated an overall decrease in the risk of visual field deterioration with increasing percentage fall in IOP postoperatively from baseline, patients who received MMC had the worst visual field survival despite having the greatest fall in IOP compared to eyes with higher postoperative IOPs following non-augmented trabeculectomy or trabeculectomy with 5FU. ${ }^{41}$ The authors postulated that the higher rate of postoperative complications, including visual acuity loss and hypotony, in the MMC group may have led to consequences that account for the greater rate of visual field progression. ${ }^{41}$
Trabeculectomy with MMC has been shown to be a good solution for congenital glaucomas unresponsive to conventional surgical treatment, such as goniotomy or trabeculotomy, with a success rate of maintaining adequate IOP control of 59 to $95 \% .{ }^{42-44}$ Although the number of patients studied was small (19 eyes of 13 patients), Mandal et al. demonstrated a 95\% complete success rate (IOP $<21 \mathrm{~mm} \mathrm{Hg}$ at slit lamp or $<16 \mathrm{~mm} \mathrm{Hg}$ with patients under general anesthesia, no progression of disk cupping and no enlargement of corneal diameter in the absence of topical glaucoma medication) with maintained visual acuity at up to 20 months following MMC-augmented trabeculectomy for primary congenital glaucoma. ${ }^{42}$ There were no cases of bleb-related infections in this series. Al-Hazmi et al. published a larger series of 150 children who underwent trabeculectomy with MMC and found $62 \%$ maintained IOP control of $<21 \mathrm{~mm} \mathrm{Hg}$ after at least 1-year follow-up. ${ }^{44}$ They did not detect any difference between $0.2 \mathrm{mg} / \mathrm{ml}$ and $0.4 \mathrm{mg} / \mathrm{ml}$ concentration of MMC with $0.4 \mathrm{mg} / \mathrm{ml}$. The rate of bleb-related infection rate in this series was $1.2 \%$. In a retrospective series of 29 patients with childhood glaucoma, Sidoti et al. observed a success rate of IOP control of $59 \%$ at 36 months, with $17 \%$ bleb-related infection rate at a mean follow-up of 28 months. The authors acknowledged that the relatively high dose of MMC exposure in their series ( $0.5 \mathrm{mg} / \mathrm{ml}$ applied for an average time of 3.8 minutes) may be related to the higher infection rate and lower IOP maintenance rate. Of all the childhood glaucomas, aphakic glaucoma has been repeatedly highlighted to have a poor success rate following MMC-augmented trabeculectomy, with a success rate of maintaining IOP of $\leq 21 \mathrm{~mm} \mathrm{Hg}$ between 0 and $37 \%,{ }^{45,46}$ and a risk ratio of failure of $2.7 .^{47}$ Age of less than 1 year at time of surgery also carries a high risk of failure. ${ }^{47}$

Trabeculectomy with MMC has an overall lower success rate in secondary glaucomas compared to primary glaucomas. In post-traumatic angle recession glaucoma, the cumulative probability of success was $85 \%$ at 1 year, decreasing to $66 \%$ at 3 years. ${ }^{48,49}$ Although uveitis is generally considered to be a risk factor for failure of glaucoma filtering surgery, ${ }^{50}$ Kaburaki et al. observed that if augmented trabeculectomy is performed in inactive uveitic eyes without prior intraocular surgery, it has a similar probability of success as patients with POAG. ${ }^{51}$ However, the presence of postoperative inflammation significantly reduced the likelihood of success. ${ }^{51}$

In neovascular glaucoma ( $\mathrm{NVG}$ ), obstruction of the trabecular meshwork by proliferating fibrovascular tissue can lead to permanent peripheral anterior synechiae, resulting in elevated IOP that is difficult to control. Trabeculectomy with MMC may be a reasonable treatment option 
for poorly controlled NVG once retinal ischemia has been treated, particularly in eyes with good visual potential. Kiuchi et al. demonstrated a cumulative probability of success following MMC-augmented trabeculectomy of $62 \%$ after 2 to 3 years in patients with NVG secondary to diabetic retinopathy. ${ }^{52}$ A similar outcome was published by Takihara et al. in a study of patients with NVG from all causes $(52 \%$ probability of success at 5 years). ${ }^{53}$ Both studies found an association between previous vitrectomy and increased likelihood of trabeculectomy failure.

Bleb needle revision following failed trabeculectomy has also been reported to have higher success when augmented with MMC. ${ }^{54-56}$ In this setting, MMC can be applied transconjunctivally after being soaked into a cellulose sponge or as a subconjunctival injection. Corneal endothelial safety has been confirmed through specular microscopic assessment of the endothelium pre- and post- MMC bleb needling. 54

In a meta-analysis assessing the role of MMC in nonpenetrating glaucoma surgery (NPGS), MMC has been identified to be associated with greater IOP reduction and greater likelihood of complete success compared to the lack of MMC use. ${ }^{57}$ The benefit of MMC is sustained at 36 months. ${ }^{57}$ Intraoperative MMC was not associated with greater risk of complications in NPGS.

There is currently no consensus of MMC use in conjunction with insertion of glaucoma drainage devices, with some authors reporting greater likelihood of surgical success with MMC ${ }^{58}$ whilst others reporting no significant difference, ${ }^{59}$ or less likelihood of success. ${ }^{60}$

\section{Mechanism of Action and Administration with 5FU}

5-fluorouracil is a pyrimidine analog which inhibits incorporation of thymidine into DNA, and interferes with RNA and ribosomal RNA synthesis. ${ }^{61}$ It has been utilized in reducing episcleral scar formation in glaucoma filtering surgery as it induces apoptosis of fibroblasts in Tenon's capsule in a time- and concentration-dependent manner. ${ }^{62}$ It is less potent than MMC in that the percentage of apoptotic cell death induced in human Tenon's fibroblasts is less when compared to MMC, even when a high dose $5 \mathrm{FU}$ is used (up to $50 \mathrm{mg} / \mathrm{ml}$ ); this is due to its less direct DNA damage compared to MMC. ${ }^{6}$ Its effects are cyclespecific and mediated primarily on proliferating cells. ${ }^{6}$ Unlike MMC, potent anti-VEGF properties have not been demonstrated..$^{54,63}$

Similar to MMC, 5FU can be applied intraoperatively under the conjunctival and scleral flaps with a typical dosage of 25 to $50 \mathrm{mg}$ for 5 minutes. ${ }^{64-66}$ Alternatively, it can be administered as repeated subconjunctival injections in the postoperative period in the office setting, with a typical dose per injection of $5 \mathrm{mg}$ in 0.1 to $0.5 \mathrm{ml}$ of saline $(5 \%) .{ }^{61}$ The number and frequency of postoperative injections depend on the clinical profile of the patient and clinical response. ${ }^{67-70}$

\section{Clinical Indications for 5FU Augmented Trabeculectomy}

The Fluorouracil Filtering Surgery Study Group observed that in patients deemed to be at higher risk of bleb failure, such as those with previous cataract surgery or failed filtration surgery, trabeculectomy is more likely to have long- term success if repeated postoperative subconjunctival 5FU injections are administered. ${ }^{69}$ The 5 -year cumulative success rate for eyes with a history of cataract surgery was $48 \%$ in the $5 \mathrm{FU}$ group and $23 \%$ in the control group $(p<0.001)$. For phakic eyes with a failed filtering procedure, the 5 -year cumulative success rate was $47 \%$ for the $5 \mathrm{FU}$ group $v s 17 \%$ for the control group $(\mathrm{p}=0.009)$. The overall risk of failure of the operation was significantly lower in the 5FU group compared to the control group (51\% vs $74 \%$, $\mathrm{p}<0.001)$. It must be noted that these investigators utilised an intensive $5 \mathrm{FU}$ regimen involving twice-daily $5 \mathrm{FU}$ injections for the first 7 postoperative days, and then daily injections from days 8 to 14 , which is far more intensive than what normally occurs within the clinical setting.

In very high-risk patients, such as those with neovascular glaucoma, trabeculectomy with adjunctive 5FU may be deemed successful initially but still has a likelihood of early failure. One study reported a median filter survival time of 39 months with a success rate of $28 \%$ at 5 years. ${ }^{71}$ Other authors reported $70 \%$ failure rate to occur within the first 2 months. ${ }^{72}$ These patients are also more likely to develop postoperative complications and poor outcomes, with $35 \%$ of patients losing light perception, and $24 \%$ developing phthisis bulbi. $^{71}$

In low-risk patients without previous intraocular surgery, it is unclear whether trabeculectomy with repeated postoperative 5FU injections improves the long-term success of the surgery when compared to trabeculectomy alone. Leyland et al. ${ }^{73}$ conducted a double-blind, randomized controlled trial comparing intraoperative application of 5FU ( $25 \mathrm{mg} / \mathrm{ml}$ for 5 minutes) to sodium chloride and identified no significant difference in IOP control at the 12 months follow-up or final follow-up (up to 52 months) in 40 eyes of 36 patients. Rothman et al. observed a cumulative 5-year success rate (IOP $\leq 21 \mathrm{~mm} \mathrm{Hg}$ ) of $78 \%$ in the $5 \mathrm{FU}$ group compared to $62 \%$ in the control group $(p=0.02) .{ }^{74}$ The Singapore 5-fluorouracil trial reported a higher proportion of patients in the 5FU group than the placebo group with success of surgery (IOP $>17 \mathrm{~mm} \mathrm{Hg}$ or $<6 \mathrm{~mm} \mathrm{Hg}$ ) at 
3 years $(p=0.0154) ;{ }^{75}$ however, at 8 years the $5 \mathrm{FU}$ group only demonstrated higher likelihood of success if failure was defined as IOP $>14 \mathrm{~mm} \mathrm{Hg}$ with or without medications $(\mathrm{p}=0.04)^{76}$

\section{Comparison between MMC and 5FU in Glaucoma Filtration Surgery}

Studies comparing the efficacy of MMC vs $5 \mathrm{FU}$ have shown variable results. In the largest prospective, randomised controlled trial comparing the two agents, Singh et al. ${ }^{65}$ reviewed the results of 108 eyes of 108 glaucoma patients with POAG, pseudoexfoliative, pigmentary, or primary angle closure glaucoma that received either trabeculectomy with intraoperative MMC $(0.4 \mathrm{mg} / \mathrm{ml}$ for 2 minutes) or intraoperative subconjunctival 5FU. Additionally, participating surgeons could also give postoperative $5 \mathrm{FU}$ injections if deemed necessary clinically. Their results demonstrated no significant difference in complete or qualified success rates between the two groups, nor were there any differences in the short- and long-term complication rates.

WuDunn et al. conducted a similar study by randomizing patients (115 eyes of 103 subjects) without prior intraocular surgery to intraoperative $5 \mathrm{FU}$ or $0.2 \mathrm{mg} / \mathrm{ml} \mathrm{MMC} \mathrm{in}$ trabeculectomy and their results also showed no significant difference between the two groups in terms of success or complication rates. This was consistent both at 12 months and long-term follow-up. ${ }^{64,77}$

However, two smaller randomized controlled trials reported different results. Singh et al. observed that the two agents were equally safe but MMC was more efficacious in a study of 85 eyes of 85 West African glaucoma patients. ${ }^{78}$ Lamping and Belkin reported the same conclusion in their study of 80 eyes of 74 pseudophakic patients with glaucoma. ${ }^{79}$

Anand and Khan looked at the efficacy of the two agents for bleb needle revision following failed trabeculectomies by retrospectively analyzing the outcomes of 98 eyes of 95 patients who underwent slit-lamp bleb-needling augmented with either MMC or $5 \mathrm{FU} .{ }^{80}$ Eyes with MMC-needling had longer bleb survival time compared to 5FU (36 months $v s$ 8 months, $\mathrm{p}=0.009) .{ }^{80}$ Sixty-one percent of eyes post MMC-needling $v s 30 \%$ of eyes post $5 \mathrm{FU}$ needling were able to maintain an IOP of 5 to $16 \mathrm{~mm} \mathrm{Hg}$ with no glaucoma medications or further procedures after 2 years. ${ }^{80}$

\section{Complications and Drawbacks of Antimetabolite Use}

Despite the evidence behind the efficacy of adjunctive antimetabolites, their use has also increased the complication rate of filtration surgery. One of the main complications is late-onset leak ( $>3$ months after surgery) related to bleb ischemia and breakdown of the conjunctiva ${ }^{81}$ Leaks are problematic because, if left untreated, they can cause vision-threatening hypotony maculopathy, shallowing of the anterior chamber, peripheral anterior synechiae, cataract formation, corneal decompensation, choroidal effusion, suprachoroidal hemorrhage and endophthalmitis. The incidence of late bleb leaks after full-thickness surgery in the pre-antimetabolite era was $3.3 \% .{ }^{82}$ This decreased with the introduction of partial thickness, guarded trabeculectomies but has been reported to have increased again with the use of antimetabolites, potentially up to as high as $30 \%$ in some series. ${ }^{11,22,24,69,83,84}$

The Moorfield's safer surgery system was developed to reduce the risks of trabeculectomy complications while maintaining its efficacy in lowering IOP. ${ }^{85}$ To reduce blebrelated complications, this system advocates two main points intraoperatively: a fornix-based (rather than a limbusbased) conjunctival incision and a larger antimetabolite treatment area. The underlying principle is to eliminate the risk factors that lead to small, avascular, cystic blebs that are more likely to leak, including limbus-based incisions, ${ }^{86}$ and small antimetabolite treatment areas. ${ }^{87}$

Mitomycin C-trabeculectomy is associated with prolonged hypotony (IOP $<6 \mathrm{~mm} \mathrm{Hg}$ for longer than 14 days $)^{88,89}$ and has a reported incidence of approximately $2.9 \% .^{90}$ If hypotony maculopathy develops, visual function will be significantly reduced and may not recover even when the hypotony is reversed. ${ }^{11}$ Hypotony is more commonly seen with higher concentration and longer exposure of MMC, presumably due to increased penetration of MMC into the ocular tissues. ${ }^{27}$ Myopia $^{91,92}$ and younger age ${ }^{88,91,92}$ are other risk factors for prolonged postoperative hypotony.

Of all the bleb-related complications, perhaps the most devastating of all is bleb-related endophthalmitis. There was great concern that the incidence of bleb-related endophthalmitis would increase significantly with the introduction of antimetabolites as adjuncts for trabeculectomy. ${ }^{93,94}$ However, concerns of an impending epidemic of blebrelated infection seem to have not manifested thus far. In the largest study of bleb-related infection to date, Yamomoto et al. ${ }^{95}$ conducted a prospective, observational cohort study of 1,098 eyes of 1,098 patients who underwent either trabeculectomy or phacotrabeculectomy augmented with MMC and reported a 5-year endophthalmitis incidence of $1.1 \%$. Infection was more commonly associated with bleb leak and younger age in this cohort. A similar incidence was reported by the collaborative initial glaucoma treatment study (CIGTS) group in their long-term review of the 300 patients randomized to the trabeculectomy arm. ${ }^{96}$ In the CIGTS, the 5-year incidence of bleb-related endophthalmitis 
was $1.1 \%$ with no significant increase in endophthalmitis risk in the patients who received adjunctive anti-fibrotics (predominantly 5FU).

Greenfield et al. ${ }^{94}$ retrospectively reviewed the course of 609 eyes of 485 patients who underwent trabeculectomy with MMC and found an endophthalmitis of rate of $2.1 \%$, occurring at a mean time of 19 months after surgery. The incidence of endophthalmitis was significantly greater following an inferior trabeculectomy compared to a superior one. These findings have been corroborated in other studies. ${ }^{97,98}$

Both 5FU and MMC can cause corneal epithelial toxicity. This is due to the anti-proliferative effect on the stem cells in the limbal region, preventing repopulation of corneal epithelium, and resulting in an epithelial defect. ${ }^{5}$ The incidence of epitheliopathy is significantly higher with $5 \mathrm{FU}$, ranging from 17 to $64 \%$, primarily due the repeated localized postoperative injections. ${ }^{8,99}$ This effect is usually limited and self-resolving but may be severe enough to cause persistent, non-healing epithelial defects. Corneal toxicity resulting from MMC can be more serious. Significant cell loss can occur during or immediately after MMC-augmented trabeculectomy. ${ }^{100}$ Inadvertent leakage of MMC at a concentration of $200 \mu \mathrm{g} / \mathrm{ml}$ results in prompt corneal swelling with marked ultrastructural alterations. ${ }^{101}$

\section{Novel Methods of Antimetabolite Delivery}

Due to the potential complications and inconsistent results associated with the current method of antimetabolite application, alternative and more controlled methods of drug delivery have been explored in recent years. However, these are still in the experimental phase and as yet, studies have not progressed outside the laboratory.

Various hydrogels have been evaluated in animal models for their ability to provide slow, sustained release of incorporated wound healing modulators to the filtration site and at the same time minimising toxicity to the surrounding tissues. P(HEMA) hydrogel loaded with MMC has been shown to inhibit conjunctival fibroblast proliferation in vitro. ${ }^{102}$ When placed in disks and attached to Ahmed glaucoma valves, it released MMC in vitro over 1 to 2 weeks and reduced bleb inflammation and fibrosis in rabbits. ${ }^{103} \mathrm{~A}$ bioactive self-assembled peptide loaded with 5FU implanted subconjunctivally adjacent to the filtration site in rabbit eyes has also demonstrated potential in terms of improving bleb survival and IOP control compared to 5FU alone. ${ }^{104,105}$

The discovery of over-expression of LDL-receptors in activated Tenon's capsule fibroblasts ${ }^{106}$ has led to research on of LDL-chitosan nanoparticles incorporated with MMC as a method of allowing safe and sustained release of
MMC following glaucoma surgery. ${ }^{107}$ This approach could potentially allow more targeted delivery of MMC as MMC is confined and protected by the chitosan nanoparticles until the particles bind to the over-expressed LDL receptors on Tenon's fibroblasts and then released. Uptake of the MMC-incorporated LDL-nanoparticles is potentially more vigorous due to the over-expressed LDL receptors. Chitosan nanoparticles are stable in human tissue and are theoretically safe but the safety and efficacy of this new system are yet to be tested in laboratory and clinical trials.

\section{CONCLUSION}

Glaucoma filtration surgery has evolved significantly over the past few decades, and antimetabolites have contributed to better outcomes in terms of postoperative IOP control. Despite advances in surgical technique, the risks associated with the use of antimetabolites in filtration surgery remain very real. Newer techniques in delivering antimetabolites are being investigated as a means of harnessing their antifibrotic properties to reliably maintain the efficacy of IOPlowering yet minimising the risk of complications. Newer agents and materials, including anti-VEGF, are among the exciting developments that may offer a similar level of IOP reduction but without the same level of risk. These will be discussed in Part 2 of this review.

\section{REFERENCES}

1. Chen CW. Enhanced intraocular pressure controlling effective ness of trabeculectomy by local application of mitomycin C. Trans Asia-Pacific Acad Ophthalmol 1983;9:172-177.

2. Gressel MG, Parrish RK 2nd, Folberg R. 5-fluorouracil and glaucoma filtering surgery: I. An animal model. Ophthalmology 1984 Apr;91(4):378-383

3. Cordeiro MF, Schultz GS, Ali RR, Bhattacharya SS, Khaw PT. Molecular therapy in ocular wound healing. Br J Ophthalmol 1999 Nov;83(11):1219-1224.

4. Skuta GL, Parrish RK 2nd. Wound healing in glaucoma filtering surgery. Surv Ophthalmol 1987 Nov-Dec;32(3):149-170.

5. Loon SC, Chew PT. A major review of antimetabolites in glaucoma therapy. Ophthalmologica 1999;213(4):234-245.

6. Crowston JG, Akbar AN, Constable PH, Occleston NL, Daniels JT, Khaw PT. Antimetabolite-induced apoptosis in Tenon's capsule fibroblasts. Invest Ophthalmol Vis Sci 1998 Feb;39(2):449-454.

7. Crowston JG, Chang LH, Constable PH, Daniels JT, Akbar AN, Khaw PT. Apoptosis gene expression and death receptor signaling in mitomycin-C-treated human tenon capsule fibroblasts. Invest Ophthalmol Vis Sci 2002 Mar;43(3):692-699.

8. Khaw PT, Doyle JW, Sherwood MB, Grierson I, Schultz G, McGorray S. Prolonged localized tissue effects from 5-minute exposures to fluorouracil and mitomycin C. Arch Ophthalmol 1993 Feb;111(2):263-267.

9. Nakamura M, Yamamoto M. DNA interstrand crosslinking agents and human ocular fibroblasts: differential sensitivity to mitomycin-C and cis-diaminedichloroplatinum(II). Exp Eye Res 1994 Jul;59(1):53-62. 
10. Lee DA, Lee TC, Cortes AE, Kitada S. Effects of mithramycin, mitomycin, daunorubicin and bleomycin on human subcon junctival fibroblast attachment and proliferation. Invest Ophthalmol Vis Sci 1990 Oct;31(10):2136-2144.

11. Skuta GL, Beeson CC, Higginbotham EJ, Lichter PR, Musch DC, Bergstrom TJ, Klein TB, Falck FY Jr. Intraoperative mitomycin versus postoperative 5-fluorouracil in high-risk glaucoma filtering surgery. Ophthalmology 1992 Mar;99(3):438-444.

12. Falck FY Jr, Skuta GL, Klein TB. Mitomycin versus 5-fluorouracil antimetabolite therapy for glaucoma filtration surgery. Semin Ophthalmol 1992;7:97-109.

13. Palmer SS. Mitomycin as adjunct chemotherapy with trabeculectomy. Ophthalmology 1991 Mar;98(3):317-321.

14. Mostafaei A. Augmenting trabeculectomy in glaucoma with subconjunctival mitomycin $\mathrm{C}$ versus subconjunctival 5-fluorouracil: a randomized clinical trial. Clin Ophthalmol 2011;5:491-494.

15. El Sayyad F, Belmekki M, Helal M, Khalil M, El-Hamzawey H, Hisham M. Simultaneous subconjunctival and subscleral mitomycin-C application in trabeculectomy. Ophthalmology 2000 Feb;107(2):298-301

16. Prata JA Jr, Minckler DS, Baerveldt G, Lee PP, Heuer DK. Site of mitomycin-C application during trabeculectomy. J Glaucoma 1994;3(4):296-301.

17. Gandolfi SA, Vecchi M, Braccio L. Decrease of intraocular pressure after subconjunctival injection of mitomycin in human glaucoma. Arch Ophthalmol 1995 May;113(5):582-585.

18. Mietz H, Addicks K, Diestelhorst M, Krieglstein GK. Extraocular application of mitomycin $\mathrm{C}$ in a rabbit model: cytotoxic effects on the ciliary body and epithelium. Ophthalmic Surg 1994 Apr;25(4):240-244.

19. Kee C, Pelzek CD, Kaufman PL. Mitomycin C suppresses aqueous humor flow in cynomolgus monkeys. Arch Ophthalmol 1995 Feb;113(2):239-242.

20. Georgopoulos M, Vass C, El Menyawi I, Radda S, Graninger W, Menapace R. In vitro diffusion of mitomycin-C into human sclera after episcleral application: impact of diffusion time. Exp Eye Res 2000 Nov;71(5):453-457.

21. Vass C, Georgopoulos M, el Menyawi I, Radda S, Nimmerrichter P. Intrascleral concentration vs depth profile of mitomycin-C after episcleral application: impact of applied concentration and volume of mitomycin-C solution. Exp Eye Res 2000 May;70(5):571-575.

22. Cheung JC, Wright MM, Murali S, Pederson JE. Intermediateterm outcome of variable dose mitomycin C filtering surgery. Ophthalmology 1997 Jan;104(1):143-149.

23. Lee SJ, Paranhos A, Shields MB. Does titration of mitomycin C as an adjunct to trabeculectomy significantly influence the intraocular pressure outcome? Clin Ophthalmol 2009;3:81-87.

24. Perkins TW, Gangnon R, Ladd W, Kaufman PL, Heatley GA. Trabeculectomy with mitomycin C: intermediate-term results. J Glaucoma 1998 Aug;7(4):230-236.

25. Megevand GS, Salmon JF, Scholtz RP, Murray AD. The effect of reducing the exposure time of mitomycin $\mathrm{C}$ in glaucoma filtering surgery. Ophthalmology 1995 Jan;102(1):84-90.

26. Neelakantan A, Rao BS, Vijaya L, Grandham SB, Krishnan N, Priya VS, Murugeshan R. Effect of the concentration and duration of application of mitomycin $\mathrm{C}$ in trabeculectomy. Ophthalmic Surg 1994 Sep-Oct;25(9):612-615.
27. Kim YY, Sexton RM, Shin DH, Kim C, Ginde SA, Ren J, Lee D, Kupin TH. Outcomes of primary phakic trabeculectomies without versus with 0.5 - to 1-minute versus 3- to 5-minute mitomycin C. Am J Ophthalmol 1998 Dec;126(6):755-762.

28. Robin AL, Ramakrishnan R, Krishnadas R, Smith SD, Katz JD, Selvaraj S, Skuta GL, Bhatnagar R. A long-term doseresponse study of mitomycin in glaucoma filtration surgery. Arch Ophthalmol 1997 Aug;115(8):969-974.

29. Vass C, Georgopoulos M, El Menyawi I, Radda S, Nimmerrichter P, Menapace R. Intrascleral concentration vs depth profile of mitomycin-C after episcleral application: impact of irrigation. Exp Eye Res 2000 Feb;70(2):139-143.

30. Kirwan JF, Lockwood AJ, Shah P, Macleod A, Broadway DC, King AJ, McNaught AI, Agrawal P. Trabeculectomy in the 21st century: a multicenter analysis. Ophthalmology 2013 Dec;120(12):2532-2539.

31. Edmunds B, Thompson JR, Salmon JF, Wormald RP. The National Survey of Trabeculectomy. II. Variations in operative technique and outcome. Eye (Lond) 2001 Aug;15(Pt 4):441-448.

32. Joshi AB, Parrish RK 2nd, Feuer WF. 2002 survey of the American Glaucoma Society: practice preferences for glaucoma surgery and antifibrotic use. J Glaucoma 2005 Apr;14(2):172-174.

33. Reibaldi A, Uva MG, Longo A. Nine-year follow-up of trabeculectomy with or without low-dosage mitomycin-C in primary open-angle glaucoma. Br J Ophthalmol 2008 Dec;92(12):1666-1670.

34. Fontana H, Nouri-Mahdavi K, Lumba J, Ralli M, Caprioli J. Trabeculectomy with mitomycin C: outcomes and risk factors for failure in phakic open-angle glaucoma. Ophthalmology 2006 Jun;113(6):930-936,

35. Beckers HJ, Kinders KC, Webers CA. Five-year results of trabeculectomy with mitomycin C. Graefes Arch Clin Exp Ophthalmol 2003 Feb;241(2):106-110.

36. Shigeeda T, Tomidokoro A, Chen YN, Shirato S, Araie M. Long-term follow-up of initial trabeculectomy with mitomycin C for primary open-angle glaucoma in Japanese patients. J Glaucoma 2006 Jun;15(3):195-199.

37. Mills KB. Trabeculectomy: a retrospective long-term follow-up of 444 cases. Br J Ophthalmol 1981 Nov;65(11):790-795.

38. Levene RZ. Glaucoma filtering surgery: factors that determine pressure control. Ophthalmic Surg 1984 Jun;15(6):475-483.

39. Jacobi PC, Dietlein TS, Krieglstein GK. Adjunctive mito mycin $\mathrm{C}$ in primary trabeculectomy in young adults: a long-term study of case-matched young patients. Graefes Arch Clin Exp Ophthalmol 1998 Sep;236(9):652-657.

40. Membrey WL, Poinoosawmy DP, Bunce C, Hitchings RA. Glaucoma surgery with or without adjunctive antiproliferatives in normal tension glaucoma: 1 intraocular pressure control and complications. Br J Ophthalmol 2000 Jun;84(6):586-590.

41. Membrey WL, Bunce C, Poinoosawmy DP, Fitzke FW, Hitchings RA. Glaucoma surgery with or without adjunctive antiproliferatives in normal tension glaucoma: 2 Visual field progression. Br J Ophthalmol 2001 Jun;85(6):696-701.

42. Mandal AK, Walton DS, John T, Jayagandan A. Mitomycin C-augmented trabeculectomy in refractory congenital glaucoma. Ophthalmology 1997 Jun;104(6):996-1003.

43. Sidoti PA, Belmonte SJ, Liebmann JM, Ritch R. Trabeculectomy with mitomycin- $\mathrm{C}$ in the treatment of pediatric glaucomas. Ophthalmology 2000 Mar;107(3):422-429. 
44. al-Hazmi A, Zwaan J, Awad A, al-Mesfer S, Mullaney PB, Wheeler DT. Effectiveness and complications of mitomycin C use during pediatric glaucoma surgery. Ophthalmology 1998 Oct;105(10):1915-1920.

45. Mandal AK, Bagga H, Nutheti R, Gothwal VK, Nanda AK. Trabeculectomy with or without mitomycin-C for paediatric glaucoma in aphakia and pseudophakia following congenital cataract surgery. Eye (Lond) 2003 Jan;17(1):53-62.

46. Azuara-Blanco A, Wilson RP, Spaeth GL, Schmidt CM, Augsburger JJ. Filtration procedures supplemented with mitomycin $\mathrm{C}$ in the management of childhood glaucoma. $\mathrm{Br} \mathrm{J}$ Ophthalmol 1999 Feb;83(2):151-156.

47. Beck AD, Wilson WR, Lynch MG, Lynn MJ, Noe R. Trabeculectomy with adjunctive mitomycin $\mathrm{C}$ in pediatric glaucoma. Am J Ophthalmol 1998 Nov;126(5):648-657.

48. Manners T, Salmon JF, Barron A, Willies C, Murray AD. Trabeculectomy with mitomycin $\mathrm{C}$ in the treatment of posttraumatic angle recession glaucoma. Br J Ophthalmol 2001 Feb;85(2):159-163.

49. Noble J, Derzko-Dzulynsky L, Rabinovitch T, Birt C. Outcome of trabeculectomy with intraoperative mitomycin $\mathrm{C}$ for uveitic glaucoma. Can J Ophthalmol 2007 Feb;42(1):89-94.

50. Panek WC, Holland GN, Lee DA, Christensen RE. Glaucoma in patients with uveitis. Br J Ophthalmol 1990 Apr;74(4):223-227.

51. Kaburaki T, Koshino T, Kawashima H, Numaga J, Tomidokoro A, Shirato S, Araie M. Initial trabeculectomy with mitomycin C in eyes with uveitic glaucoma with inactive uveitis. Eye (Lond) 2009 Jul;23(7):1509-1517.

52. Kiuchi Y, Sugimoto R, Nakae K, Saito Y, Ito S. Trabeculectomy with mitomycin $\mathrm{C}$ for treatment of neovascular glaucoma in diabetic patients. Ophthalmologica 2006;220(6):383-388.

53. Takihara $Y$, Inatani $M$, Fukushima $M$, Iwao K, Iwao $M$, Tanihara H. Trabeculectomy with mitomycin $\mathrm{C}$ for neovascular glaucoma: prognostic factors for surgical failure. Am J Ophthalmol 2009 May;147(5):912-918.

54. Maestrini HA, Cronemberger S, Matoso HD, Reis JR, Mérula RV, Filho AD, Sakurai E, Ferreira GA. Late needling of flat filtering blebs with adjunctive mitomycin C: efficacy and safety for the corneal endothelium. Ophthalmology 2011 Apr;118(4):755-762.

55. Iwach AG, Delgado MF, Novack GD, Nguyen N, Wong PC. Transconjunctival mitomycin- $\mathrm{C}$ in needle revisions of failing filtering blebs. Ophthalmology 2003 Apr;110(4):734-742.

56. Mardelli PG, Lederer CM Jr, Murray PL, Pastor SA, Hassanein KM. Slit-lamp needle revision of failed filtering blebs using mitomycin C. Ophthalmology 1996 Nov;103(11):1946-1955.

57. Cheng JW, Cai JP, Li Y, Wei RL. Intraoperative mitomycin C for nonpenetrating glaucoma surgery: a systematic review and meta-analysis. J Glaucoma 2011 Jun-Jul;20(5):322-326.

58. Alvarado JA, Hollander DA, Juster RP, Lee LC. Ahmed valve implantation with adjunctive mitomycin $\mathrm{C}$ and 5-fluorouracil: long-term outcomes. Am J Ophthalmol 2008 Aug;146(2):276284.

59. Costa VP, Azuara-Blanco A, Netland PA, Lesk MR, Arcieri ES. Efficacy and safety of adjunctive mitomycin $\mathrm{C}$ during Ahmed Glaucoma Valve implantation: a prospective randomized clinical trial. Ophthalmology 2004 Jun;111(6):1071-1076.

60. Al-Mobarak F, Khan AO. Two-year survival of Ahmed valve implantation in the first 2 years of life with and with out intraoperative mitomycin C. Ophthalmology 2009 Oct;116(10):1862-1865.
61. Abraham LM, Selva D, Casson R, Leibovitch I. The clinical applications of fluorouracil in ophthalmic practice. Drugs 2007;67(2):237-255.

62. Khaw PT, Sherwood MB, MacKay SL, Rossi MJ, SchultzG. Five-minute treatments with fluorouracil, floxuridine and mitomycin have long-term effects on human Tenon's capsule fibroblasts. Arch Ophthalmol 1992 Aug;110(8):1150-1154.

63. Smith S, D'Amore PA, Dreyer EB. Comparative toxicity of mitomycin $\mathrm{C}$ and 5-fluorouracil in vitro. Am J Ophthalmol 1994 Sep;118(3):332-337.

64. Palanca-Capistrano AM, Hall J, Cantor LB, Morgan L, Hoop J, WuDunn D. Long-term outcomes of intraoperative 5-fluorouracil versus intraoperative mitomycin $\mathrm{C}$ in primary trabeculectomy surgery. Ophthalmology 2009 Feb;116(2):185-190.

65. Singh K, Mehta K, Shaikh NM, Tsai JC, Moster MR, Budenz DL, Greenfield DS, Chen PP, Cohen JS, Baerveldt GS, et al. Trabeculectomy with intraoperative mitomycin $\mathrm{C}$ versus 5-fluorouracil. Prospective randomized clinical trial. Ophthalmology 2000 Dec;107(12):2305-2309.

66. Towler HM, McCluskey P, Shaer B, Lightman S. Longterm follow-up of trabeculectomy with intraoperative 5-fluorouracil for uveitis-related glaucoma. Ophthalmology 2000 Oct;107(10):1822-1828.

67. Heuer DK, Parrish RK 2nd, Gressel MG, Hodapp E, Desjardins DC, Skuta GL, Palmberg PF, Nevárez JA, Rockwood EJ. 5-Fluorouracil and glaucoma filtering surgery. III. Intermediate follow-up of a pilot study. Ophthalmology 1986 Dec;93(12):1537-1546.

68. Ruderman JM, Welch DB, Smith MF, Shoch DE. A randomized study of 5-fluorouracil and filtration surgery. Am J Ophthalmol 1987 Sep;104(3):218-224.

69. The Fluorouracil Filtering Surgery Study Group. Five-year follow-up of the Fluorouracil Filtering Surgery Study. Am J Ophthalmol 1996 Apr;121(4):349-366.

70. Goldenfeld M, Krupin T, Ruderman JM, Wong PC, Rosenberg LF, Ritch R, Liebmann JM, Gieser DK. 5-Fluorouracil in initial trabeculectomy. A prospective, randomized, multicenter study. Ophthalmology 1994 Jun;101(6):1024-1029.

71. Tsai JC, Feuer WJ, Parrish RK 2nd, Grajewski AL. 5-Fluorouracil filtering surgery and neovascular glaucoma. Long-term follow-up of the original pilot study. Ophthalmology 1995 Jun;102(6):887-893.

72. Rockwood EJ, Parrish RK 2nd, Heuer DK, Skuta GL, Hodapp E, Palmberg PF, Gressel MG, Feuer W. Glaucoma filtering surgery with 5-Fluorouracil. Ophthalmology 1987 Sep;94(9):1071-1078.

73. Leyland M, Bloom P, Zinicola E, McAlister J, Rassam S, Migdal C. Single intraoperative application of 5-Fluorouracil versus placebo in low-risk trabeculectomy surgery: a randomized trial. J Glaucoma 2001 Dec;10(6):452-457.

74. Rothman RF, Liebmann JM, Ritch R. Low-dose 5-fluorouracil trabeculectomy as initial surgery in uncomplicated glaucoma: long-term follow-up. Ophthalmology 2000 Jun;107(6):11841190 .

75. Wong TT, Khaw PT, Aung T, Foster PJ, Htoon HM, Oen FT, Gazzard G, Husain R, Devereux JG, Minassian D, et al. The Singapore 5-fluorouracil trabeculectomy study: effects on intraocular pressure control and disease progression at 3 years. Ophthalmology 2009 Feb;116(2):175-184. 
76. Wong MH, Husain R, Ang BC, Gazzard G, Foster PJ, Htoon HM, Wong TT, Oen FT, Khaw PT, Seah SK, et al. The Singapore 5-fluoro uracil trial: intraocular pressure outcomes at 8 years. Ophthalmology 2013 Jun;120(6):1127-1134.

77. WuDunn D, Cantor LB, Palanca-Capistrano AM, Hoop J, Alvi NP, Finley C, Lakhani V, Burnstein A, Knotts SL. A prospective randomized trial comparing intraoperative 5 -fluorouracil vs mitomycin C in primary trabeculectomy. Am J Ophthalmol 2002 Oct;134(4):521-528.

78. Singh K, Egbert PR, Byrd S, et al. Trabeculectomy with intraoperative 5-fluorouracil vs mitomycin C. Am J Ophthalmol 1997 Jan;123(1):48-53.

79. Lamping KA, Belkin JK. 5-fluorouracil and mitomycin C in pseudophakic patients. Ophthalmology 1995 Jan;102(1):70-75.

80. Anand N, Khan A. Long-term outcomes of needle revision of trabeculectomy blebs with mitomycin $\mathrm{C}$ and 5-fluorouracil: a comparative safety and efficacy report. J Glaucoma 2009 Sep;18(7):513-520.

81. Greenfield DS, Liebmann JM, Jee J, Ritch R. Late-onset bleb leaks after glaucoma filtering surgery. Archives of Ophthalmology 1998 Apr;116(4):443-447.

82. Lamping KA, Bellows AR, Hutchinson BT, Afran SI. Longterm evaluation of initial filtration surgery. Ophthalmology 1986 Jan;93(1):91-101.

83. Katz GJ, Higginbotham EJ, Lichter PR, et al. Mitomycin C vs 5 -fluorouracil in high-risk glaucoma filtering surgery. Extended follow-up. Ophthalmology 1995 Sep;102(9):1263-1269.

84. Ticho U, Ophir A. Late complications after glaucoma filtering surgery with adjunctive 5-fluorouracil. Am J Ophthalmol 1993 100. Storr-Paulsen T, Norregaard JC, Ahmed S, Storr-Paulsen A. Apr 15;115(4):506-510.

85. Dhingra S, Khaw PT. The moorfields safer surgery system. Middle East Afr J Ophthalmol 2009 Jul;16(3):112-115.

86. Wells AP, Cordeiro MF, Bunce C, Khaw PT. Cystic bleb formation and related complications in limbus vs fornix-based conjunctival flaps in pediatric and young adult trabeculectomy with mitomycin C. Ophthalmology 2003 Nov;110(11): 2192-2197.

87. Cordeiro MF, Constable PH, Alexander RA, Bhattacharya SS, Khaw PT. Effect of varying the mitomycin $\mathrm{C}$ treatment area in glaucoma filtration surgery in the rabbit. Investigative Ophthalmol and Visual Science 1997 Jul;38(8):1639-1646.

88. Kupin TH, Juzych MS, Shin DH, Khatana AK, Olivier MM. Adjunctive mitomycin $\mathrm{C}$ in primary trabeculectomy in phakic eyes. Am J Ophthalmol 1995 Jan;119(1):30-39.

89. Zacharia PT, Deppermann SR, Schuman JS. Ocular hypotony after trabeculectomy with mitomycin C. Am J Ophthalmol 1993 Sep 15;116(3):314-326.

90. Costa VP, Wilson RP, Moster MR, Schmidt CM, Gandham S. Hypotony maculopathy following the use of topical mitomycin C in glaucoma filtration surgery. Ophthalmic Surgery 1993 Jun;24(6):389-394.

91. Stamper RL, McMenemy MG, Lieberman MF. Hypotonous maculopathy after trabeculectomy with subconjunctival 5-fluorouracil. Am J Ophthalmol 1992 Nov 15;114(5):544-553.
92. Seah SK, Prata JA Jr, Minckler DS, Baerveldt G, Lee PP, HeuerDK. Hypotony following trabeculectomy. J Glaucoma 1995 Apr;4(2):73-79.

93. Katz LJ, Cantor LB, Spaeth GL. Complications of surgery in glaucoma. Early and late bacterial endophthalmitis following glaucoma filtering surgery. Ophthalmology 1985 Jul;92(7): 959-963.

94. Greenfield DS, Suner IJ, Miller MP, Kangas TA, Palmberg PF, Flynn HW Jr. Endophthalmitis after filtering surgery with mitomycin. Archives of Ophthalmology 1996 Aug;114(8): 943-949.

95. Yamamoto T, Sawada A, Mayama C, et al. The 5-year incidence of bleb-related infection and its risk factors after filteringsurgeries with adjunctive mitomycin C: collaborative bleb- related infection incidence and treatment study 2 . Ophthalmology 2014 May;121(5):1001-1006.

96. Zahid S, Musch DC, Niziol LM, Lichter PR. Risk of endophthalmitis and other long-term complications of trabeculectomy in the collaborative initial glaucoma treatment study (CIGTS).Am J Ophthalmol 2013 Apr;155(4):674-680.

97. Higginbotham EJ, Stevens RK, Musch DC, et al. Bleb-related endophthalmitis after trabeculectomy with mitomycin C. Ophthalmology 1996 Apr;103(4):650-656.

98. Song A, Scott IU, Flynn HW Jr, Budenz DL. Delayed-onset bleb-associated endophthalmitis: clinical features and visual acuity outcomes. Ophthalmology 2002 May;109(5):985-991.

99. The fluorouracil filtering surgery study group. Fluorouracil filtering surgery study one-year follow-up. Am J Ophthalmol 1989 Dec 15;108(6):625-635.

100. Storr-Paulsen T, Norregaard JC, Ahmed S, Storr-Paulsen A. Corneal endothelial cell loss after mitomycin C-augmented trabeculectomy. J Glaucoma 2008 Dec;17(8):654-657.

101. McDermott ML, Wang J, Shin DH. Mitomycin and the human corneal endothelium. Archives of Ophthalmology 1994 Apr;112(4):533-537.

102. Blake DA, Sahiner N, John VT, et al. Inhibition of cell proliferation by mitomycin $\mathrm{C}$ incorporated into P(HEMA) hydrogelsJ Glaucoma 2006 Aug;15(4):291-298.

103. Sahiner N, Kravitz DJ, Qadir R, et al. Creation of a drugcoated glaucoma drainage device using polymer technology:in vitro and in vivo studies. Archives of Ophthalmology 2009 Apr;127(4):448-453.

104. Liang L, Xu XD, Zhang XZ, Feng M, Peng C, Jiang FG. Prevention of filtering surgery failure by subconjunctival injection of a novel peptide hydrogel into rabbit eyes. Biomedical Materials 2010 Aug;5(4):045008 (p. 8).

105. Xu XD, Liang L, Chen CS, et al. Peptide hydrogel as an intraocular drug delivery system for inhibition of postoperative scarring formation. ACS applied materials and interfaces 2010 Sep;2(9):2663-2671.

106. Chen HY, Ge J, Guo Y, Jin CJ, Lan YQ, Lin MK. The inhibition effect of photodynamic on human Tenon capsule fibroblast cells. (Zhonghua yan ke za zhi) Chinese J Ophthalmology 2003 Mar;39(3):160-162.

107. Shao T, Li X, Ge J. Target drug delivery system as a new scar ring modulation after glaucoma filtration surgery. Diagnostic Pathology 2011;6:64. . 